\section{Comparisons of Root Morphology in Susceptible and Tolerant Melon Cultivars before and after Infection by Monosporascus cannonballus}

\author{
Kevin Crosby ${ }^{1}$ \\ Vegetable Improvement Center, Department of Horticultural Sciences, Texas \\ A\&M University, College Station, TX 77843 \\ David Wolff ${ }^{2}$ and Marvin Miller ${ }^{3}$ \\ Texas Agricultural Experiment Station, 2415 East Highway 83, Weslaco, \\ TX 78596
}

Additional index words. muskmelon, honeydew, root rot, ascospores, fungus, Cucumis melo

\begin{abstract}
The fungus Monosporascus cannonballus Pollock and Uecker infects melon (Cucumis melo L.) roots and causes root rot/vine decline disease, which has reduced productivity of commercial muskmelon and honeydew cultivars in South Texas. To assess the impact of the fungus on several root traits, two greenhouse experiments were carried out over two seasons. A comparison of inoculated vs. control root systems was carried out with four melon cultivars representing both susceptible ('Magnum 45' and 'Caravelle') and tolerant types ('Deltex' and 'Doublon'). The sand medium was inoculated with 50-60 colony forming units (CFUs) per gram of the severe Monosporascus strain, TX90-25. After a 30-day growth period, the control and inoculated root systems were carefully cleaned and evaluated. Roots were scanned by a computer and the data were analyzed by the Rhizo Pro 3.8 program. The traits of interest included total root length, average root diameter, number of root tips, number of fine roots $(0-0.5 \mathrm{~mm})$, and number of small roots $(0.5-1$ $\mathrm{mm})$. Significant differences existed between the two tolerant cultivars and the two susceptible ones for four of the traits. Total root length, fine and small root length, and root tip number were greater for 'Deltex' than for both susceptible cultivars and greater for 'Doublon' than for 'Caravelle'. The results suggest that tolerance to this pathogen is closely linked to the integrity of the root structure. The potential for improving root vigor to combat root rot/vine decline merits further investigation.
\end{abstract}

About 3500 ha of honeydew and cantaloupe melons (Cucumis melo. $\mathrm{L}$ ) are grown in the Rio Grande Valley of South Texas annually. The subtropical climate allows early planting and the earliest harvest in the continental United States. The profitability of the crop has helped it to survive the economic pressures that have reduced or eliminated production of other vegetables in the region.

The greatest threat to melon production has been losses due to vine decline diseases. Numerous fungi attack roots, stems, and fruit,

Received for publication 22 Oct. 1998. Accepted for publication 17 Apr. 1999. Research conducted at the Texas Agricultural Experiment Station, Weslaco. Use of trade names does not imply endorsement of the products named nor criticism of similar ones not named. We thank Rick Hernandez, Cory Dombrowski, Kay Harding, and Arnold Olivares for their valuable help in maintaining greenhouse and field experiments. The cost of publishing this paper was defrayed in part by the payment of page charges. Under postal regulations, this paper therefore must be hereby marked advertisement solely to indicate this fact.

${ }^{1}$ Graduate Research Assistant; e-mail: K-Crosby@ tamu.edu.

${ }^{2}$ Plant Breeder; current address: Sakata Seeds America, P.O. Box 1118, Lehigh, FL 33970.

${ }^{3}$ Professor of Plant Pathology. causing crop loss. One of the most devastating diseases in recent years is root rot/vine decline caused by Monosporascus cannonballus (Martyn and Miller, 1996). This fungus inhabits the calcareous soils of South Texas and other hot, dry regions. Distribution is widespread in cultivated soils with high $\mathrm{pH}$, and ascospores are extremely heat- and droughttolerant (Stanghellini et al., 1996). The fungus kills roots at all stages of development (Mertely et al., 1991), leading to excessive stress on the vines, which decline or collapse. This problem is exacerbated by fruit load, heat, drought, and physiological stresses (Wolff, 1996). Replicated field trials and germplasm screening have identified both tolerant and highly susceptible cultivars (Cohen et al., 1996; Wolff and Miller, 1998). Many other cultivars fall into an intermediate category but none exhibit immunity. In addition to field tests, several greenhouse experiments have been conducted with different strains of $M$. cannonballus and high inoculum levels (Wolff and Miller, 1997).

Breeding might improve root structures and thereby increase tolerance to Monosporascus root rot/vine decline. Prior to conducting genetic analyses, differences in root structure need to be confirmed. The first objective of our experiments was to determine if differences in root morphology existed be- tween susceptible and tolerant melon cultivars. The second objective of our experiments was to identify the effects of severe $M$. cannonballus infections on root morphology of tolerant vs. susceptible cultivars of melons.

\section{Materials and Methods}

Four melon cultivars were selected based on previous field evaluations for tolerance to M. cannonballus. Both 'Deltex', an ananas type, and 'Doublon', a charentais type, have exhibited tolerance to the fungus in field and greenhouse tests (Wolff and Miller, 1997). 'Magnum 45', a western shipper type, is a standard susceptible control used in many trials (Mertely et al., 1991). 'Caravelle', also a western shipper, is a popular commercial hybrid that is extremely susceptible to the disease.

These four cultivars were grown in two separate experiments, in the same greenhouse in Weslaco, Texas, over consecutive summers, 1997 and 1998. All materials and techniques were the same for both experiments unless otherwise noted.

The virulent $M$. cannonballus strain, TX 90-25, was maintained on V8 agar in plastic petri plates (Mertely et al., 1991). A sand/oat hull mixture $(500 \mathrm{~g})$ was placed into plastic storage boxes and autoclaved $4 \times$ for $20 \mathrm{~min}$. Each box of sterilized medium was then inoculated under a laminar flow hood with 10 plugs of the V8 agar containing M. cannonballus mycelia. The inoculum was shaken once a week for 4 weeks while the fungus developed, after which colony forming unit (CFU) counts were measured by a standard 1000 -fold dilution on petri plates of potato dextrose agar with no streptomycin (Mertely et al., 1993)

Prior to sowing the seed, the sand media was pasteurized at $72^{\circ} \mathrm{C}$ for $10 \mathrm{~h}$ in order to kill other potential pathogens. The $\mathrm{pH}$ of the sand was 8.5 to 9.0 , which was favorable for $M$. cannonballus growth (Mertely et al., 1993). The sand/oat hull inoculum was added to the pasteurized sand in a rotating cement mixer, using $50 \mathrm{CFU}$ of $M$. cannonballus per gram of sand in 1997. In order to insure maximum disease pressure, this was increased to $60 \mathrm{CFU}$ in 1998.

Black plastic pots $(12 \mathrm{~L})$ were filled with the inoculated sand within $5 \mathrm{~cm}$ of the top. An additional $2.5 \mathrm{~cm}$ of pasteurized sand was then added to provide a buffer zone for germination to prevent immediate inoculation and death of the seedlings. Control pots were filled with pasteurized sand. Osmocote ${ }^{\circledR}$ (Scotts-Sierra, Marysville, Ohio) 7.7 N-6.1 P-11.6 K (28 g) was mixed into the top $5 \mathrm{~cm}$ of sand in each pot. On 10 July 1997 and 25 June 1998 pots were sown with seed from the four cultivars and arranged in a randomized complete-block design with four (1997) or seven (1998) replications (blocks). Three pots per cultivar were grown in each replication. Seedling emergence was examined each day and the growth period begun accordingly. Two treatments, inoculated and control, were grown side by side in the greenhouse for $30 \mathrm{~d}$. Plants were 
hand-watered with $1 \mathrm{~L}$ of tap water every 3 or $4 \mathrm{~d}$ based on temperature and moisture content of the sand. In addition, each plant received $600 \mathrm{~mL}$ of Peters 9.1 N-8.7 P-16.6 K (400 $\left.\mathrm{mg} \cdot \mathrm{L}^{-1}\right)$, plus micronutrients every $7 \mathrm{~d}$ throughout the growth period.

All plants were harvested in a $24-\mathrm{h}$ period. After cutting the vine and removing the pot, each root system was carefully placed in a fine mesh cage and submerged in a 200-L drum of water. This allowed all of the sand to flow out, leaving only the roots. Entire root systems and all fragments were carefully blotted dry on paper towels and placed in sealable plastic bags for storage at $4{ }^{\circ} \mathrm{C}$. Over the next $6 \mathrm{~d}$, each root system was carefully placed on a clear glass plate and submerged in a thin layer of water. All roots were evenly spread apart, and the plate was placed on a HP Scanjet $4 \mathrm{c}$ wide scanner (Hewlett Packard, Palo Alto, Calif.). The roots were then scanned using a computer program, Rhizo 3.8 Pro, by Regent Instruments (Quebec, Quebec, Canada). Rhizo 3.8 Pro generates values for total root length, average root diameter, number of root tips, and length of roots in specific diameter classes. All data were analyzed using SAS 6.12 (SAS Institute, 1995). Analysis of variance (ANOVA) and mean separations for all root traits examined were generated using the GLM and Means/LSD commands.

\section{Results and Discussion}

Expt. 1. 1997. The ANOVA revealed significant differences among cultivars and between treatments. In addition, interaction was significant for total root length and number of root tips. The most significant differences involved total root length, number of root tips, and length of fine $(0-0.5 \mathrm{~mm})$ diameter roots (Table 1). Coefficients of variation were reasonable except for average root diameter and root length $(0.5-1.0 \mathrm{~mm})$, which were $39 \%$ and $32 \%$, respectively.

Differences between control and inoculated roots were nonsignificant for either of the two tolerant cultivars, 'Deltex' and 'Doublon', except that inoculation reduced the number of root tips in the former (Table 1). In contrast, in the two susceptible cultivars, 'Magnum' and 'Caravelle', control and inoculated roots differed significantly for each trait except average diameter. 'Caravelle' had the greatest root damage, with $46 \%$ reduction for root length and $66 \%$ reduction for root tip number, and 'Doublon' the least, with only $5 \%$ reduction in total root length and $1 \%$ reduction in fine root length $(0-0.5 \mathrm{~mm})$

The four cultivars differed little when not inoculated (Table 1). Only root tip number varied significantly, with 'Deltex' having significantly more than 'Magnum' or 'Doublon.' Cultivar differences were much greater following inoculation. Root length was significantly greater in the two tolerant cultivars than in the two susceptible ones. Both 'Deltex' and 'Doublon' had significantly greater root tip numbers and fine root length than did 'Caravelle.' 'Doublon' also had significantly greater root tip numbers and length of larger

Table 1. Separation of means among four cultivars for five root traits and two treatments over 2 years. LS means interaction between treatments. ${ }^{z}$ Mean separations within treatments. ${ }^{y}$

\begin{tabular}{|c|c|c|c|c|c|c|}
\hline \multirow[b]{2}{*}{ Treatment } & \multirow[b]{2}{*}{ Cultivar } & \multirow{2}{*}{$\begin{array}{c}\text { Total } \\
\text { length }^{z} \\
(\mathrm{~cm}) \\
\end{array}$} & \multirow{2}{*}{$\begin{array}{c}\text { No. of } \\
\text { root tips }\end{array}$} & \multirow{2}{*}{$\begin{array}{l}\text { Avg diam } \\
(\mathrm{cm})\end{array}$} & \multicolumn{2}{|c|}{$\begin{array}{l}\text { Length }(\mathrm{cm}) \text { of roots }{ }^{y} \\
\text { with diam of }\end{array}$} \\
\hline & & & & & $0-0.5 \mathrm{~mm}$ & $0.5-1.0 \mathrm{~mm}$ \\
\hline & \multicolumn{6}{|c|}{1997} \\
\hline \multirow{4}{*}{$\begin{array}{l}\text { Control } \\
\text { roots }\end{array}$} & Deltex & $2,909 \mathrm{a}$ & $10,685 \mathrm{a}$ & $0.045 \mathrm{a}$ & $2,235 \mathrm{a}$ & $589 \mathrm{a}$ \\
\hline & Caravelle & $2,768 \mathrm{a}$ & $9,320 \mathrm{ab}$ & $0.047 \mathrm{a}$ & $1,941 \mathrm{a}$ & $585 \mathrm{a}$ \\
\hline & Magnum & $2,628 \mathrm{a}$ & $8,236 \mathrm{~b}$ & $0.044 \mathrm{a}$ & $2,102 \mathrm{a}$ & $580 \mathrm{a}$ \\
\hline & Doublon & $2,386 \mathrm{a}$ & $8,233 \mathrm{~b}$ & $0.046 \mathrm{a}$ & $1,788 \mathrm{a}$ & $516 \mathrm{a}$ \\
\hline \multirow{5}{*}{$\begin{array}{l}\text { Inoculated } \\
\text { roots }\end{array}$} & Deltex & $2,513 \mathrm{a}$ & $6,809 \mathrm{bc}$ & $0.048 \mathrm{a}$ & $1,852 \mathrm{a}$ & $565 \mathrm{ab}$ \\
\hline & Caravelle & $1,426 \mathrm{~b}$ & $3,147 \mathrm{~d}$ & $0.072 \mathrm{a}$ & $1,042 \mathrm{c}$ & $321 \mathrm{ab}$ \\
\hline & Magnum & $1,764 \mathrm{~b}$ & $6,040 \mathrm{c}$ & $0.040 \mathrm{a}$ & $1,403 \mathrm{bc}$ & $316 \mathrm{~b}$ \\
\hline & Doublon & $2,499 \mathrm{a}$ & $8,897 \mathrm{~b}$ & $0.049 \mathrm{a}$ & $1,797 \mathrm{ab}$ & $592 \mathrm{a}$ \\
\hline & \multicolumn{6}{|c|}{1998} \\
\hline \multirow{4}{*}{$\begin{array}{l}\text { Control } \\
\text { roots }\end{array}$} & Deltex & 4,204 a & $11,755 \mathrm{ab}$ & $0.031 \mathrm{~cd}$ & $3,117 \mathrm{a}$ & $641 \mathrm{a}$ \\
\hline & Caravelle & $3,751 \mathrm{ab}$ & $10,158 \mathrm{bc}$ & $0.033 \mathrm{bc}$ & $2,813 a b$ & $609 \mathrm{a}$ \\
\hline & Magnum & $4,051 \mathrm{ab}$ & $12,485 \mathrm{a}$ & $0.029 \mathrm{~d}$ & 3,165 a & $584 \mathrm{a}$ \\
\hline & Doublon & $3,085 \mathrm{~b}$ & $9,093 \mathrm{c}$ & $0.035 \mathrm{~b}$ & $2,356 \mathrm{~b}$ & $510 \mathrm{a}$ \\
\hline \multirow{4}{*}{$\begin{array}{l}\text { Inoculated } \\
\text { roots }\end{array}$} & Deltex & $1,818 \mathrm{c}$ & $5,352 \mathrm{~d}$ & $0.035 \mathrm{~b}$ & $1,536 \mathrm{a}$ & 303 a \\
\hline & Caravelle & $664 \mathrm{e}$ & $1,973 \mathrm{f}$ & $0.097 \mathrm{a}$ & $647 \mathrm{c}$ & $110 \mathrm{c}$ \\
\hline & Magnum & 902 de & 2,822 ef & $0.053 \mathrm{~b}$ & 814 bc & $137 \mathrm{bc}$ \\
\hline & Doublon & $1,554 \mathrm{~cd}$ & $4,937 \mathrm{de}$ & $0.036 \mathrm{~b}$ & $1,306 \mathrm{ab}$ & $268 \mathrm{ab}$ \\
\hline
\end{tabular}

${ }^{2}$ Comparison of means between treatments. Control ' $a$ ' = inoculated 'a.'

${ }^{y}$ Comparison of means within treatments. Control ' $a$ ' $\neq$ inoculated ' $a$.'

roots $(0.5-1.0 \mathrm{~mm})$ than did 'Magnum' while 'Deltex' had significantly greater fine root length than did 'Magnum.'

Interaction between cultivar and treatment was evident in the data for total root length and number of root tips (Table 1). Root length differences between cultivars were relatively small (maximum difference 19\%) when not inoculated, but significant differences were evident following inoculation. Root length was reduced only $14 \%$ and $10 \%$ in 'Deltex' and 'Doublon' (tolerant), respectively, vs. 33\% and $40 \%$ in 'Magnum' and 'Caravelle' (susceptible), respectively. Similar trends were evident for number of root tips (Table 1).

Expt. 2. 1998. The significant changes in design for 1998 included the addition of three more replications and an increased level of fungal inoculum. The data (Table 1) are based only on plants that survived the experiment. All 'Deltex' and 'Doublon' plants survived, but two each of the 'Magnum' and 'Caravelle' plants died. Significant or highly significant cultivar differences were evident for average root diameter, number of root tips, and length of fine roots $(0-0.5 \mathrm{~mm})$. Highly significant differences existed between treated and control roots for every root trait. The dramatic difference between control and inoculated roots is visible in Fig. 1. There were also significant interactions between cultivar and treatment for three of the five traits: total root length, average root diameter, and number of root tips.

Treatment differences were significant for all parameters measured. Inoculation did not affect average root diameter in 'Doublon' but increased diameter in the other three cultivars because of loss of fine roots. Percent reductions in total, fine, and narrow root length were much greater for the two susceptible cultivars than for the two tolerant ones. Total root length was reduced $82 \%$ and $78 \%$ for 'Caravelle' and 'Magnum,' respectively, vs. 57\% and 50\%, respectively, for 'Deltex' and 'Doublon'. 'Doublon' exhibited the lowest percentage reductions for all five root traits.

In the control, few significant differences existed among the four cultivars for the five root traits (Table 1). The exceptions include smaller average diameter in 'Magnum' than in 'Caravelle' or 'Doublon', and in 'Deltex' than in 'Doublon', and less total and fine root length in 'Doublon' than in 'Deltex'. In addition, 'Doublon' had significantly fewer root tips and less fine root length than did 'Magnum'.

The inoculated roots exhibited many more significant differences (Table 1). 'Deltex' had greater total root length, number of root tips, fine root length $(0-0.5 \mathrm{~mm})$, and small root length $(0.5-1.0 \mathrm{~mm})$ than 'Caravelle' and 'Magnum'. 'Doublon' was significantly greater than 'Caravelle' but not 'Magnum' for the same traits. 'Magnum' was not significantly higher than 'Caravelle' for the same four traits. 'Caravelle' was significantly higher in average root diameter than the other three cultivars due to loss of fine roots.

The interaction of cultivar and treatment was most evident with total root length. Differences were much smaller in control roots (maximum 26\%) as compared to inoculated roots (maximum 64\%). Once again, the differences between control and inoculated roots were smaller for the tolerant cultivars, 'Deltex' and 'Doublon' (57\% and 50\%, respectively), as compared to the susceptible cultivars 'Magnum' and 'Caravelle' (78\% and 82\%, respectively). The same trends were apparent for number of root tips and average diameter. The maximum difference was $23 \%$ in control roots as compared to $63 \%$ in inoculated roots. The $54 \%$ and $46 \%$ reductions in number of root tips for 'Deltex' and 'Doublon,' respectively, were much less than the $77 \%$ and $81 \%$ reductions for 'Magnum' and 'Caravelle', respectively. 'Caravelle' was a large source of variation for the average root diameter in inoculated roots. The extreme susceptibility to inoculation and subsequent loss of fine roots in 

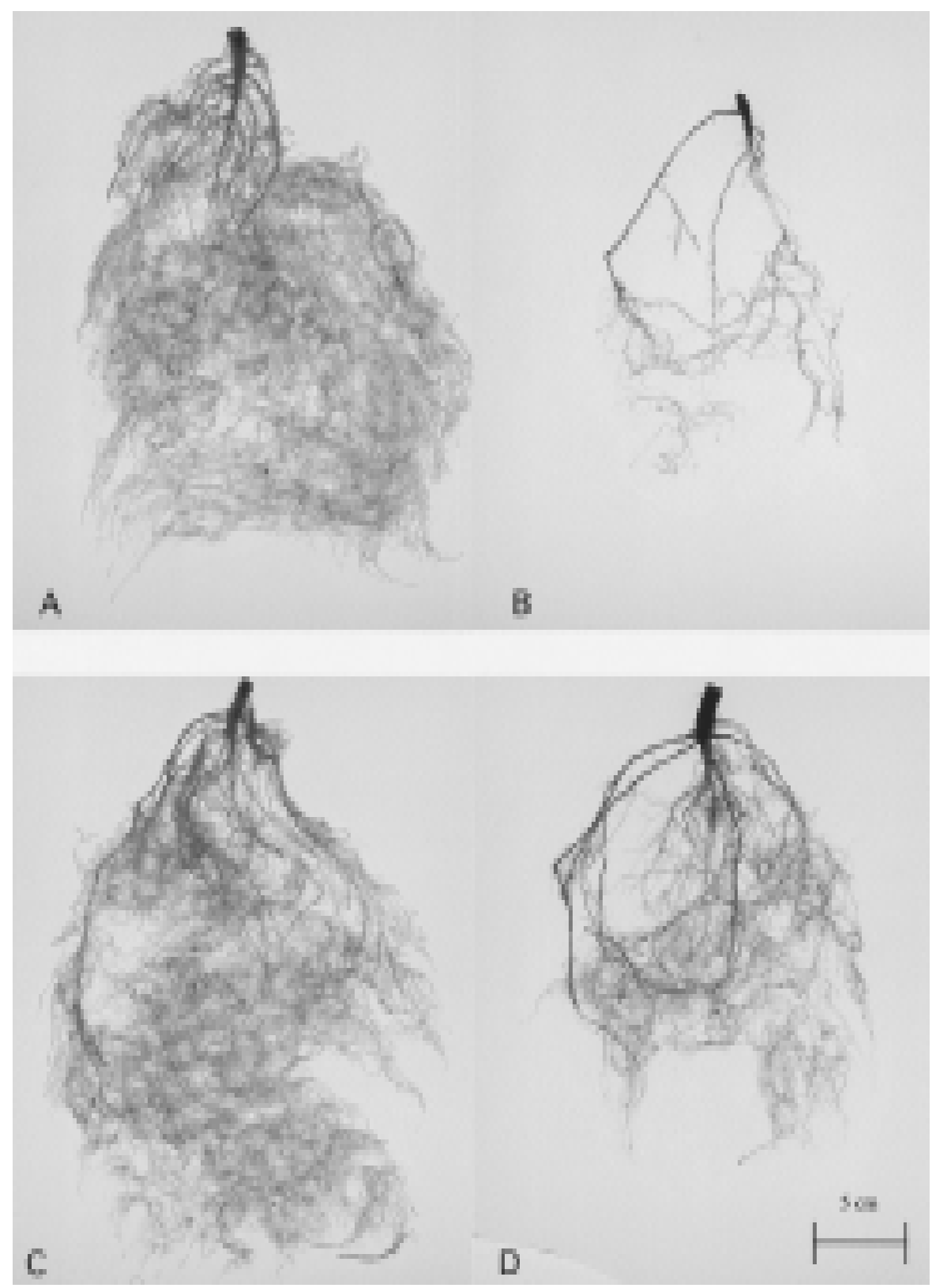

Fig 1. Root systems of $(\mathbf{A}, \mathbf{C})$ healthy and $(\mathbf{B}, \mathbf{D})$ Monosporascus cannonballus-inoculated melon cultivars $(\mathbf{A}, \mathbf{B})$ 'Caravelle' and $(\mathbf{C}, \mathbf{D})$ 'Deltex'.

this cultivar was the reason this value was so high $(0.09 \mathrm{~cm})$. This was an obvious source of the interaction variance. In contrast, inoculated roots of 'Deltex' and 'Doublon' were only $5 \%$ and $13 \%$ different, respectively, than control roots.

These results are interesting in light of the field evaluations for tolerance to $M$. cannonballus. The general lack of significant differences for the root traits examined in healthy roots is somewhat surprising. The higher total root length and fine root values for 'Deltex' may not be significant because of a relatively small data set. However, we have observed a similar trend for these traits in 'Deltex' in several root evaluations (data not shown). These trends in both 'Deltex' and 'Doublon' stress tolerance. This may also be true in melon. Under the stress of infection by this fungus, 'Deltex' and 'Doublon' have greater root lengths and numbers of fine roots than the two more susceptible cultivars. The increased capacity for water and nutrient absorption associated with greater surface area may be an important factor in the tolerance to M. cannonballus. Research to evaluate the genetic control of this tolerance and the root traits examined is currently under way. In alfalfa, several root traits were examined in diallel experiments by Johnson et al. (1996); these traits had moderate to high heritabilities, indicating the existence of additive genetic variation. This type of variation may indicate additive gene action, and predictable expression of the traits in the progeny. The measurement and analysis of genetic variation for the melon root traits and their impact on disease tolerance will reveal the amount of additive genetic variation available and the effectiveness of selecting for improved root phenotypes. This will be the next step in developing new cultivars able to withstand infection by M. cannonballus.

\section{Literature Cited}

Cohen, R., Y. Elkind, Y. Burger, R. Offenbach, and H. Nerson. 1996. Variation in the response of melon genotypes to sudden wilt. Euphytica 87:91-95.

Johnson, L.D., J.J. Marquez-Ortiz, D.K. Barnes, and J.F.S. Lamb. 1996. Inheritance of root traits in alfalfa. Crop Sci. 36:1482-1487.

Martyn, R.D. and M.E. Miller. 1996. Monosporascus root rot and vine decline: An emerging disease of melons worldwide. Plant Dis. 80:716-725.

Mertely, J.C., R.D. Martyn, M.E. Miller, and B.D. Bruton. 1991. Role of Monosporascus cannonballus and other fungi in a root rot/vine decline disease of muskmelon. Plant Dis. 75:1133-1137.

Mertely, J.C., R.D. Martyn, M.E. Miller, and B.D. Bruton. 1993. Quantification of Monosporascus cannonballus ascospores in commercial muskmelon fields in South Texas. Plant Dis. 77:766771.

Pantalone, V.R., G.J. Rebetzke, J.W. Burton, and T.E. Carter, Jr. 1996. Phenotypic evaluation of root traits in soybean and applicability to plant breeding. Crop Sci. 36:456-459.

Stanghellini, M.E., D.H. Kim, and S.L. Rasmussen. 1996. Ascospores of Monosporascus cannonballus: Germination and distribution in cultivated and desert soils in Arizona. Phytopathology 86:509-514.

were more obvious following inoculation with the fungus. The difference between 'Deltex' and 'Caravelle' is obvious in Fig. 1. The superior performance of 'Deltex' and 'Doublon' root systems corresponds well with the field tolerance observed in soils naturally infested with $M$. cannonballus, and suggests the existence of some resistance mechanism. Whether this mechanism involves chemical or physiological responses to infection or just increased root vigor remains to be seen. Pantalone et al. (1996) associated increased fibrous root area with improved drought tolerance and nitrogen fixation in soybean [Glycine $\max (\mathrm{L}$.) Merrill]. They proposed that greater root surface area is a selectable characteristic that contributes to superior vigor and
Wolff, D.W. and M.E. Miller. 1997. Evaluation of MRRVD field tolerant lines and hybrids in the tems in South Texas, Texas A\&M Univ. System, Agr. Res. Ext. Ctr., Weslaco.

Wolff, D.W. and M.E. Miller. 1998. Tolerance to Monosporascus root rot and vine decline in melon (Cucumis melo L.) germplasm. HortScience 33:287-290.

Wolff, D.W. 1996. Genotype, fruit load, and temperature affect Monosporascus root rot/vine decline symptom expression in melon (Cucumis melo L.), p. 280-284. In: M.L. GomezGuillamon, C. Soria, J. Cuartero, J.A. Tores, and R. Fernandez-Munoz (eds.). Cucurbits towards 2000: Proc. 7thEucarpia Mtg. on Cucurbit Genet. and Breeding. C.S.I.C., Malaga, Spain. field and greenhouse. Melon production sys- 